\title{
Intracerebral Hemorrhage, Visual Hallucination and COVID-19: What Is the Connection? A Case-Related Review of the Literature on Peduncular Hallucinosis Following Intracerebral Hemorrhage
}

\author{
Nicolas M. Nagysomkuti Mertse ${ }^{1, *}$, Lisa Zenorini ${ }^{2}$ and René Müri $^{1}$ (D) \\ 1 Department of Neurology, Inselspital, Bern University Hospital, University of Bern, 3012 Bern, Switzerland; \\ rene.mueri@insel.ch \\ 2 Department of Geriatric Psychiatry, University Hospital of Psychiatry, University of Bern, \\ 3012 Bern, Switzerland; Lisa.zenorini@upd.ch \\ * Correspondence: nicolas.nagysomkutimertse@insel.ch; Tel.: +41-31-308-8345
}

Citation: Nagysomkuti Mertse, N.M.; Zenorini, L.; Müri, R. Intracerebral Hemorrhage, Visual Hallucination and COVID-19: What Is the Connection? A Case-Related Review of the Literature on Peduncular Hallucinosis Following Intracerebral Hemorrhage. Clin. Transl. Neurosci. 2021, 5, 15. https:// doi.org/10.3390/ctn5020015

Academic Editor:

Dominik Straumann

Received: 11 June 2021

Accepted: 6 August 2021

Published: 12 August 2021

Publisher's Note: MDPI stays neutral with regard to jurisdictional claims in published maps and institutional affiliations.

Copyright: (c) 2021 by the authors. Licensee MDPI, Basel, Switzerland. This article is an open access article distributed under the terms and conditions of the Creative Commons Attribution (CC BY) license (https:// creativecommons.org/licenses/by/ $4.0 /)$.

\begin{abstract}
Previous publications have discussed the occurrence of intracerebral hemorrhages, hallucinations and psychosis in COVID-19 patients. In this article, we have reviewed the literature on the subject while depicting the case of a 63-year-old female patient who suffered from an intracerebral hemorrhage in the right basal ganglia and thalamus two weeks after a COVID-19 diagnosis and who developed a visual hallucinosis shortly after. We concluded that, while there may be a correlation between COVID-19 and hallucinations according to current literature, more research is yet needed to clarify. In our case, we rather interpreted the hallucinations in the context of a peduncular hallucinosis related to the intracerebral hemorrhage. We compared our patient's lesion localization to other 15 reported cases of peduncular hallucinations following intracerebral hemorrhages reported on Pubmed. In summary, the lesions were localized in the pons in $52.9 \%$ of the cases, $17.7 \%$ were in the thalamus and/or the basal ganglia, $17.7 \%$ in the mesencephalon and respectively $5.8 \%$ in the temporal and occipital lobe. The distribution pattern we found is consistent with the previously proposed mechanism behind peduncular hallucinations.
\end{abstract}

Keywords: peduncular hallucinosis; intracerebral hemorrhage; COVID-19; psychosis

\section{Introduction}

Hallucinations are defined as sensory perceptions in the absence of a corresponding external stimulus [1,2]. This scientific and rather dry understanding of hallucinations reflects little of the magic that surrounded visions and voice hearing in other cultural context throughout the history of mankind, as depicted beautifully in various mythologies and religious scriptures.

The concept of hallucination as a manifestation of a medical condition dates back to the 17th century, when the French physician François Fernel first used the word "hallucination" in his book "la pathologie" to describe visual alterations due to various afflictions of the cornea [3]. The first "modern" definition of hallucinations covering different sensory modalities was formulated in 1817 by the French Psychiatrist Jean-Etienne Esquirol $[4,5]$.

As the definition of the word evolved over the centuries, so did our understanding of this phenomenon's importance in neuropsychiatric disorders. Hallucinations are nowadays an indispensable part of modern psychopathological nomenclature [2]. Along with other psychotic symptoms, they can be found in multiple neuropsychiatric conditions like dementia, delirium and schizophrenia [6], but also in infectious diseases like viral encephalitis [7]. The coronavirus SARS-Cov-2, which has been in the focus of research interest since the recent outbreak 2019/2020, has also been found to target the brain [8], provoking neuropsychiatric complications in $22.5 \%$ of COVID-19 patients [9]. A causal 
relationship between psychosis and $\mathrm{c}$ infections has been discussed in the past and is still the object of controversial debates [9-11].

It is in light of this debate that we now present the case of a 63-year-old female patient who developed an intracerebral hemorrhage and psychotic symptoms with visual hallucinations while suffering from a severe pneumonia following a SARS-CoV-2-infection. Based on our case report and the existing literature, we will briefly discuss the clinical features of and the possible mechanism behind COVID-19 related intracerebral hemorrhage, psychosis, hallucinations and a case-related selection of differential diagnoses.

\section{Case History}

The 63-year-old right-handed female patient was initially sent to the emergency room by her family doctor with a suspected pulmonary embolism after having suffered from dyspnea and edema in the legs for 3 days prior to hospitalization. Physical examination showed signs of venous congestion. Her blood test showed a hypopotassemia $(2.9 \mathrm{mmol} / \mathrm{L})$, elevated CRP, bicytopenia with low thrombocytes and erythrocytes, elevated d-dimers and elevated liver enzymes as well as an INR-elevation up to 1.46. A CAT-scan showed an atypical left basal lobar pneumonia with right sided dorso-basal pleural effusions and a cardiomegaly. Further diagnostic also revealed a Child-Pugh A liver cirrhosis with an umbilical bypass circuit, which after exclusion of other differential diagnoses was ascribed to regular alcohol consumption. The patient was put under treatment with vitamin B1, B12 and folic acid, though now substrate deficiency could be objectified.

A few days after admission, the patient developed a delirium that was attributed to alcohol withdrawal and successfully treated with lorazepam. Following two initial negative tests, a third smear PCR confirmed the suspected COVID-19 diagnosis a week after hospital admission. Shortly after, the initially displayed slight respiratory insufficiency objectified by blood gas analysis worsened and had to be compensated with up to $6 \mathrm{~L}$ of oxygen per minute in order to maintain the saturation above $90 \%$. The patient was therefore transferred to the ICU, where she was intubated for ventilation and later on received a tracheotomy.

On the 14th day of hospitalization, she suddenly developed an anisocoria and a right sided hemiparesis. The MRI showed an acute intracerebral hemorrhage in the right-sided basal ganglia and thalamus (Figure 1). The source of the bleeding could not be determined, nor did the images present any vascular malformation. A coagulation analysis showed increased D-Dimer-levels (3874 ug/L), low platelets $(83 \mathrm{G} / \mathrm{L})$, a prolonged prothrombin time with an INR of 1.23 and a slightly elevated level of fibrinogen $(4.06 \mathrm{~g} / \mathrm{L})$. A lumbar cerebrospinal fluid analysis showed a slight pleocytosis $(7 \mathrm{M} / \mathrm{L})$ as well as elevated protein$(3.06 \mathrm{~g} / \mathrm{L})$ and glucose $(4.83 \mathrm{~g} / \mathrm{L})$ levels. SARS-CoV-2-RNA could not be objectified.

The patient was treated by EVD-implantation and transferred to neurorehabilitation six weeks later. At the time, she presented a left-sided hemiparesis and a left-sided multimodal neglect. While her orientation was intact in all qualities, she showed important mnestic deficits that she compensated through confabulations. She also presented formal thought disorders including perseverations, semantic paraphasia and distractible speech embedded in a general psychomotor slowdown. During neurorehabilitation she recurrently reported vivid visual hallucinations in the shape of animals (a white, black and brown spotted cat walking around in her room, ants crawling up the wall) as well as people (her granddaughter wearing a bright blue dress). The hallucinations were not perceived as threatening, though the patient could not always identify them as hallucinations. She also recurrently mistook the personnel for family members. This initial delusional misidentification later evolved into an intense feeling of familiarity. The patient, a former teacher, subsequently assumed that the nurses were former students of hers. At times, she also claimed to feel that her husband was waiting for her on the ward, right outside of her room. Since the symptoms did not disturb the patient and did not interfere with the rehabilitation, we refrained from giving an antipsychotic medication. 

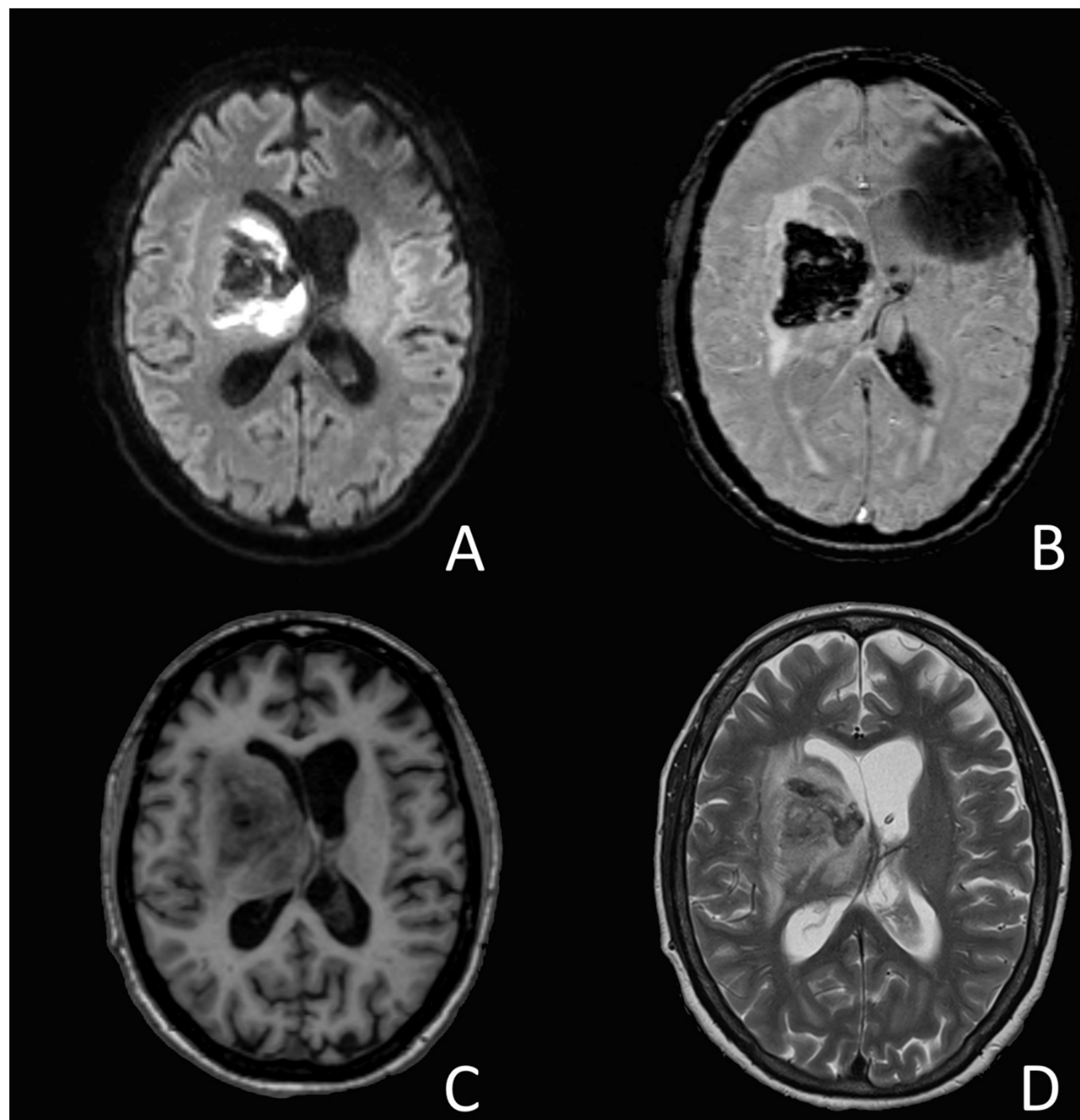

Figure 1. Cranial MRI one day after ICH diagnosis. (A) Diffusion weighted imaging (DWI) with $\mathrm{b}=1000 \mathrm{~s} / \mathrm{mm}^{2}$; (B) Susceptibility weighted imaging (SWI); (C) T1-weighted MRI; (D) T2-weighted MRI. Partially diffusion-restricted, T2-inhomogenous, T1-iso-/-hyperintense intracerebral hemorrhage within the right basal ganglia with subsequent midline shift and compression of the right lateral ventricle and of the third ventricle (not included in the pictures). The susceptibility artifact in picture (B) (left side, fronto-temporal) is related to the EVD-implantation. In the same picture, a significant blood collection can be seen in the occipital horn of the left lateral ventricle. Microbleeds could not be objectified.

\section{Discussion}

\subsection{COVID-19 Related Intracerebral Hemorrhage_or Not?}

According to a study by Mao et al. [12], intracerebral hemorrhages (ICH) have been observed in only $0.4 \%$ of the sampled COVID-19 patients. Beyond this study, the data available on the incidence of ICH occurring in COVID-19 is scarce, with a high heterogeneity across publications [13-16]. The few reported cases seem to share clinical features. In a case 
series, Benger et al. [17] pointed out, that the patients who developed an ICH following COVID-19 are relatively young compared to average ICH-patients (41-64 years [17] vs. 60-80 years in average population [18]), had elevated d-dimers (1420-7580 ng/mL), a history of hypertension and no vascular malformation in MRI [17]. Unlike in our patient though, the hemorrhages reported in the case series were mostly superficial with only one out of five patients showing deep-structure bleedings [17]. A recently submitted review of 123 COVID-19 cases with neurological events suggests a different distribution pattern though. Parsons et al. [19] found a linear distribution pattern of these events, including microbleeds, radiating from the cerebellum and the basal ganglia towards other central nervous system structures [19]. Considering the association between microbleeds and spontaneous ICH [20,21], the latter might be more frequent within deep structures in COVID-19 patients than suggested in the case series by Benger et al. [17].

The presumed cell-invasion mechanism of SARS-COV-2 via the endothelial ACE2receptor found in many organs including the brain [22-24] supports the thesis of a correlation between COVID-19 and ICH. By adhesion, the virus lowers the anti-inflammatory and anti-oxidative effect conveyed by the receptor [23]. In patients with chronic conditions like diabetes or hypertension, this combination of additional oxidative stress, inflammation, hypertension and the damage to the blood-brain-barrier following the budding of new viruses could indeed hypothetically lead to hemorrhages within the cerebral tissue $[25,26]$. Ultimately though, the evidence at hand does not suffice to state a correlation between COVID-19 and ICH. In our case, considering the patients history, other causes of ICH, like hypertension or hepatic coagulopathy, should be considered. The laboratory results (elevated INR, the elevated liver enzymes, low thrombocytes), the lack of microbleeds as a sign of chronic hypertensive encephalopathy as well as the lack of objectified hypertensive emergencies during hospitalization prior to the bleeding makes an association to the liver cirrhosis with a subsequently impaired coagulation cascade seem likely.

\subsection{Visual Hallucination and Intracerebral Bleeding: A Portrait of Peduncular Hallucinosis}

Structural damage of the brain (e.g., trauma, stroke, bleeding or tumor) can lead to various syndromes involving visual hallucinations. Some of these syndromes are defined by the context in which the hallucinations appear. Charles-Bonnet-Syndrome, for instance, refers to visual hallucinations in patients with partial visual field defects; Anton-Babinskisyndrome involves confabulations in patients with bilateral cortical blindness. Vivid visual hallucinations without visual impairment, as described in our case, are typical in peduncular hallucinosisb [6]. These can result from various conditions affecting the brain including autoimmune, infectious, oncological and vascular pathologies, but are most commonly associated with stroke [27]. The hallucinations usually start a few days after the event, lasting from several minutes up to several hours, and may fade away after a few weeks. In some cases though, they persist over several years [5]. They typically consist in vivid and colorful representations of people and animals, sometimes deformed or miniaturized (Lilliputians). Most patients have insight in the hallucinatory nature of the scenes. The hallucinations are often associated with sleep disturbances [5].

The name hallucinose pédonculaire (French for peduncular hallucinosis) was first proposed in a publication by Van Bogaert in 1927 [28]. While the historical name persisted and is still nowadays commonly used in literature, new cases reported throughout the past century showed that the phenomenon is not limited to peduncular lesions but can be found in various brain lesions.

We conducted a research on reports of patients experiencing visual hallucinations after cerebral hemorrhages in order to determine the common locations of the lesions in patients with ICH-associated peduncular hallucinosis (Figure 2). We searched the PubMed library using the terms 'Peduncular' 'hallucinosis' 'intracerebral' 'hemorrhage' (seven results) and 'cerebral' 'bleeding' 'visual' 'hallucination' (73 results). 


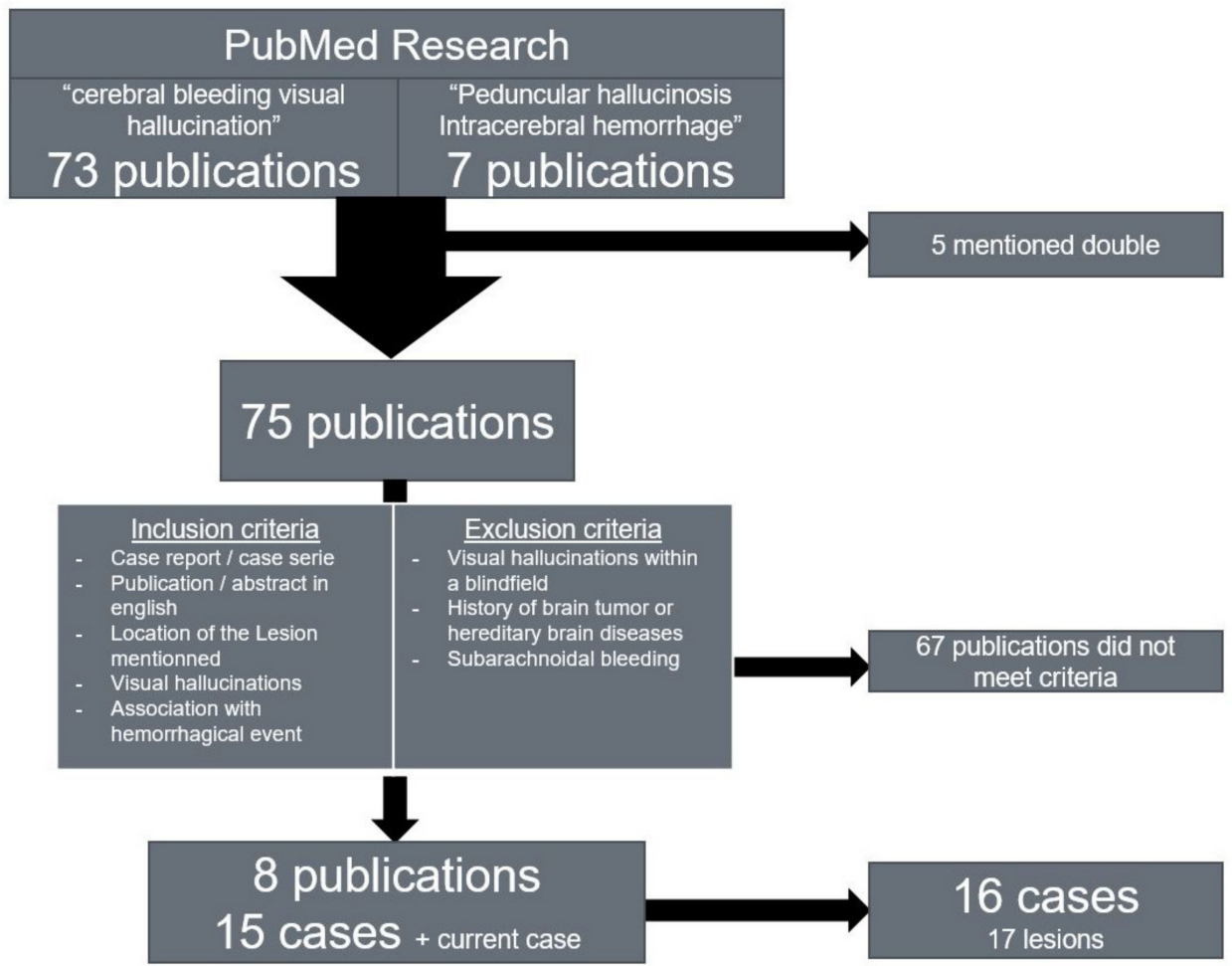

Figure 2. Pubmed research.

We included free access publications in English depicting cases of patients presenting visual hallucinations following cerebral hemorrhage and mentioning the location of the lesion including the side. When available, English abstracts of publications in other languages were included if they met the inclusion criteria. One case with a history of brain tumor was discarded due to the extensive brain damage depicted in the case [29]. We also discarded cases with hallucinations with Charles-Bonnet syndrome and cases of subarachnoid hemorrhage, since the hallucinations described are presumed to be associated with delayed cerebral ischemia rather than with the bleeding itself [30]. We found 16 sufficiently documented cases in the publications listed below (Table 1).

Table 1. Distribution of the lesions in cases of intracerebral hemorrhage-related peduncular hallucinosis $(n=17)$.

\begin{tabular}{ccccc}
\hline Localization & Right & Left & Bilateral & Total \\
\hline $\begin{array}{c}\text { Mesencephalon } \\
(+ \text { internal capsule in 1 case) }\end{array}$ & $2[31,32]$ & $1[33]$ & $/$ & $3(17.7 \%)$ \\
\hline Thalamus/basal ganglia & $2[34]$, current case & $1[35]$ & $/$ & $3(17.7 \%)$ \\
\hline Occipital lobe & $1[36]$ & $/$ & $/$ & $1(5.8 \%)$ \\
\hline Pontine & $3[37]$ & $1[33]$ & $5[37]$ & $9(52.9 \%)$ \\
\hline Temporal lobe & $1[38]$ & $/$ & $/$ & $1(5.8 \%)$ \\
\hline
\end{tabular}

The lesion pattern we found is consistent with the presumed mechanism behind peduncular hallucinosis described by Manford and Andermann [39] in their review on complex visual hallucinations. According to their model, structural or functional damage of afferent serotonergic inhibitory pathways issued from the raphe nuclei may indirectly increase the effect of the excitatory input issued from the pedunculopontine tegmental nucleus (PPTN) towards supratentorial structures involved in the processing of visual information, notably thalamic structures (thalamic reticular nucleus, lateral geniculate node), primary visual and visual association cortices. As part of the reticular activating 
system, the PPTN is subject to spontaneous excitatory outbursts that, with the loss of the filtering inhibition conveyed by the raphe nuclei, might manifest themselves as visual hallucinations (Figure 3A,B). These pathways also seem to play an important role in the transition between sleep stages, which would explain the sleep disturbances often found in peduncular hallucinosis.

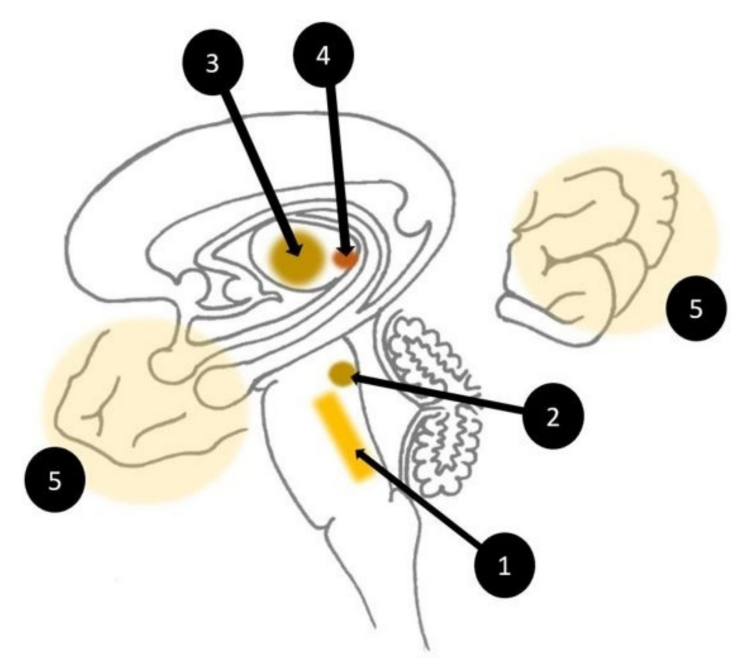

\section{Raphe nuclei $(\mathrm{RN})$}

2. Pedunculopontine tegmental nucleus (PPTN)

\section{Thalamic reticular nucleus (TRN)}

4. Lateral geniculate node (LGN)

\section{Cerebral cortex}

(A)

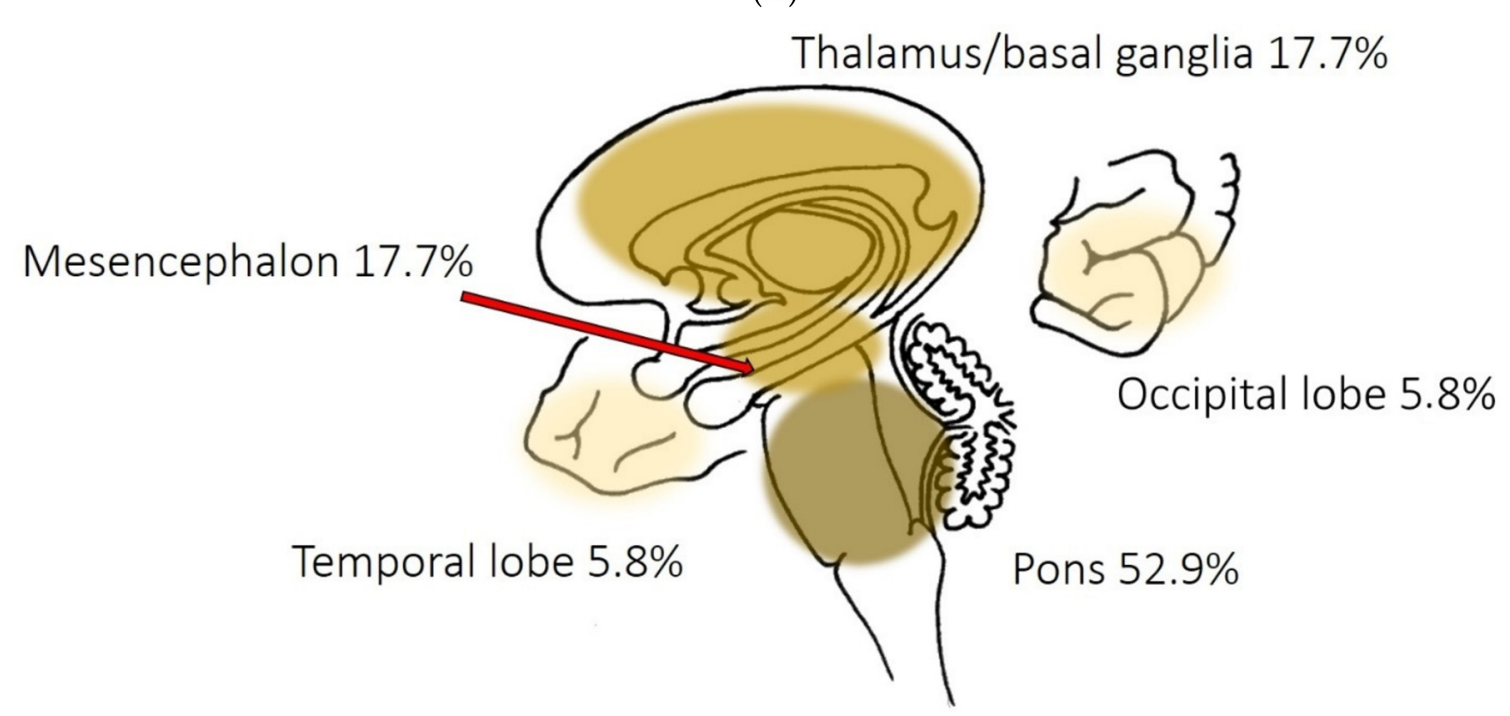

(B)

Figure 3. (A) Anatomy of the structures presumably involved in peduncular hallucinosis and (B) distribution pattern of intracerebral hemorrhages in intracerebral hemorrhage-related peduncular hallucinosis.

\subsection{COVID-19, Psychosis and Hallucinations}

An association between exposure to coronaviruses and psychotic symptoms has already been suggested in 2011 by Severance et al. [11].The recent interest in coronaviruses following the COVID-19 pandemic brought up numerous new publications on potential neuropsychiatric complications.

One of these studies, published in August 2020 by Nalleballe et al. [9], estimated neuropsychiatric manifestations to occur in $22.5 \%$ of all COVID-19 patients. This estimation was based on the data from a sample of over 40.000 COVID-19 patients. Psychiatric 
complications with an incidence down to $0.2 \%$ of the sampled COVID-19 patients (suicidal ideation) were included. Although the authors mentioned a possible strong relationship between COVID-19 and psychosis, the latter was not mentioned in their list of psychiatric complications found in the sample. The authors mentioned that their data on psychiatric complications was limited. Assuming that few COVID-19 patients were primarily seen and reported by a psychiatrist, a bias due to the medical specialization of the reporting clinicians should be considered. In a more recent British surveillance study [40] on collaboration with the Royal College of Psychiatry and the Association of British Neurologists published in October 2020 in The Lancet, new-onset psychosis was described in 8\% (10) of the 153 reported COVID-19 cases with neuropsychiatric complications. In that study, seventeen percent of the reporting physicians were psychiatrists.

The occurrence of hallucinations in or following a COVID-19 has scarcely been investigated so far. The first study in which a larger sample of COVID-19 patients was systematically screened for neuropsychiatric manifestations including hallucinations was only published in December 2020 in Nature. In this study by Mirfazeli et al. [41], approximately $11 \%$ of the included 201 patients with a confirmed COVID-19 diagnosis reported visual or auditory hallucinations. A potential relationship with delirium states was discussed, but the authors rather suggested an interpretation of the phenomenon in the context of neuroinflammation, considering the seemingly low correlation between hallucinations and disorientation in their sample. A German post mortem study by Matschke et al. [42] indeed found neuroimmune activation in all of the sampled deceased patients with most prominent changes within the brainstem, which supports this interpretation. Interestingly, the cross-analysis of the neuropsychiatric symptoms performed by Mirfazeli et al. [41] showed an important correlation between hallucinations and stroke. In the sample of Matschke et al. [42], COVID-19-related ischemic strokes were mostly found within the territory of the posterior cerebral artery which supplies precisely the structures presumably involved in the emergence of peduncular hallucinosis. It is thus conceivable, that some of the hallucinations found in the sample of Mirfazeli et al. have appeared in the context of peduncular hallucinosis following stroke.

Prior to the paper of Mirfazeli et al. [41] there were only a few reports of hallucinations in COVID-19, which is surprising considering the incidence of over $10 \%$ found in their sample. The distribution of microbleeds [19], stroke and neuroinflammatory changes [42] found in COVID-19 also suggests a high incidence of peduncular hallucinations among COVID-19 patients. Hallucinations, especially peduncular hallucinations, might have been underreported by both patients and physicians or even overseen in the past due to their benign character compared to other complications of COVID-19, intracerebral hemorrhage or ischemic stroke.

An important problem of the studies mentioned above may be potential side effects of the drugs administrated in COVID-19. Severe cases are often treated with hydroxychloroquine and corticosteroids. Cases of drug-induced psychosis have already been reported for both drugs prior to the COVID-19 pandemic [43,44]. Hydroxychloroquine, corticosteroids or other potentially psychoactive drugs administrated during treatment may therefore have been responsible at least for some of the psychotic symptoms reported in COVID-19 patients, including hallucinations [45-47].

\subsection{Visual Hallucinations and Alcoholic Hallucinosis}

Seeing pink elephants is a commonly used euphemism in English-speaking areas to describe a state of extreme drunkenness. It refers to alcohol-induced visual hallucinations of pink elephants and blue mice described by the American author Jack London in his autobiographical novel 'John Barleycorn' published in 1913 picturing his experiences and struggle with alcoholism [48].

Visual hallucinations can indeed be found in many syndromes related to alcohol including alcoholic intoxication with delirium, alcoholic hallucinosis or delirium tremens as well as other less common syndromes like Wernicke-Korsakoff syndrome or hepatic 
encephalopathy [49]. Few of these various syndromes fit in the context of our case, yet one of them constitutes an important differential diagnosis considering our patients history of regular alcohol consumption.

Alcoholic hallucinosis refers to a phenomenon often following alcohol withdrawal in which patients are subject to mostly auditory and/or sometimes vivid visual hallucinations often accompanied by paranoia and fear [50]. Their sensorium is usually intact, though some mild signs of confusion may be found. The hallucinations begin 24 to $48 \mathrm{~h}$ after withdrawal and usually resolve within 30 days, but may last for several months [50,51].

The emergence of these hallucinations is attributed to an autonomic hyperarousal conveyed by an increased dopamine activity found in both alcoholic intoxication and withdrawal [52], which explains the similarity of the hallucinatory experience in acute alcoholic intoxication with delirium ("pink elephants") and in alcoholic hallucinosis. Alcohol is known to increase the dopamine levels in certain brain structures, an effect that also seems to play an important part in the emergence of addiction [53]. In heavy drinkers, the sudden lack of alcohol leads to a decrease in dopamine activity following withdrawal [53]. The dopamine level increases again a few days later, probably in the context of an autonomic compensatory upregulation, and may thus induce hallucinations [54]. This delayed dopamine activity increase explains the latency between withdrawal and hallucination onset typical in alcoholic hallucinosis.

\section{Conclusions}

The presumed cell-invasion mechanism of SARS-CoV-2 suggests an increased vulnerability for intracerebral hemorrhages, yet the evidence at hand does not suffice to state a correlation between COVID-19 and ICH. In our case, the hemorrhage was most likely related to the ethyltoxic liver cirrhosis with a subsequently impaired coagulation cascade and low thrombocytes.

We interpret the hallucinations our patient reported in the context of a peduncular hallucinosis following the intracerebral hemorrhage. The latency of 8 weeks between alcohol withdrawal and onset of the hallucinations as well as the treatment with benzodiazepines makes an alcoholic hallucinosis less likely.

The data available on the correlation between psychosis and COVID-19 are ambiguous and insufficient to discriminate properly the underlying cause of the psychotic symptoms some patients seem to have developed during their infection with SARS-CoV-2. Previous studies on coronaviruses suggest a synergetic trigger-effect between infection, personal susceptibility and medication [11,47]. The correlation between COVID-19 and hallucinations also remains unclear. COVID-19 related hallucinations might be underreported, considering the findings discussed above. A systematic neuropsychiatric assessment of COVID-19 patients based on standardized psychiatric tools (e.g., Mini International Neuropsychiatric Interview) under consideration of case, medication and family history may improve our understanding of the connection between psychosis, hallucinations and COVID-19.

Funding: This research received no external funding.

Institutional Review Board Statement: The study was conducted according to the guidelines of the Declaration of Helsinki, and approved by the Ethics Committee of (Req-2021-00700; date of approval: 21 June 2021).

Informed Consent Statement: Informed consent was obtained from all subjects involved in the study.

Data Availability Statement: Publicly available datasets were analyzed in this study. This data can be found on PubMed (see citations 31-38). Supplementary data related to the reported case are available on request from the corresponding author.

Conflicts of Interest: The authors declare no conflict of interest. 


\begin{tabular}{ll}
\multicolumn{2}{l}{ Abbreviations } \\
ICH & intracerebral hemorrhage \\
PPTN & pedunculopontine tegmental nucleus \\
COVID-19 & Coronavirus disease 2019
\end{tabular}

\section{References}

1. Arciniegas, D.B. Psychosis. Continuum 2015, 21, 715-736. [CrossRef]

2. Calabrese, J.; Al Khalili, Y. Psychosis (Nursing); StatPearls: Treasure Island, FL, USA, 2020.

3. Fernel, J. La Pathologie de Jean Fernel: Ouvrage Tres-Utile à Tous Ceux qui S'appliquent à la Connoissance du Corps Humain; Vve Jean Le Bouc, Quai des Augustins: Paris, France, 1646.

4. Telles-Correia, D.; Moreira, A.L.R.; Gonçalves, J.S. Hallucinations and related concepts-Their conceptual background. Front. Psychol. 2015, 6, 991. [CrossRef] [PubMed]

5. Collerton, D.; Perry, E.K.; Mosimann, U.P. The Neuroscience of Visual Hallucinations; Wiley Blackwell: Chichester, UK; Hoboken, NJ, USA, 2015.

6. Teeple, R.C.; Caplan, J.P.; Stern, T.A. Visual hallucinations: Differential diagnosis and treatment. Prim. Care Companion. J. Clin. Psychiatry 2009, 11, 26-32. [CrossRef]

7. Ramírez-Bermúdez, J.; Soto-Hernández, J.L.; López-Gómez, M.; Mendoza-Silva, M.; Colin-Piana, R.; Campillo-Serrano, C. Frecuencia de signos y síntomas neuropsiquiátricos en pacientes con encefalitis viral. Rev. Neurol. 2005, 41, 140-144. [CrossRef] [PubMed]

8. Wu, Y.; Xu, X.; Chen, Z.; Duan, J.; Hashimoto, K.; Yang, L.; Liu, C.; Yang, C. Nervous system involvement after infection with COVID-19 and other coronaviruses. Brain Behav. Immun. 2020, 87, 18-22. [CrossRef] [PubMed]

9. Nalleballe, K.; Onteddu, S.R.; Sharma, R.; Dandu, V.; Brown, A.; Jasti, M.; Yadala, S.; Veerapaneni, K.; Siddamreddy, S.; Avula, A.; et al. Spectrum of neuropsychiatric manifestations in COVID-19. Brain Behav. Immun. 2020, 88, 71-74. [CrossRef]

10. Tariku, M.; Hajure, M. Available Evidence and Ongoing Hypothesis on Corona Virus (COVID-19) and Psychosis: Is Corona Virus and Psychosis Related? A Narrative Review. Psychol. Res. Behav. Manag. 2020, 13, 701-704.

11. Severance, E.G.; Dickerson, F.B.; Viscidi, R.P.; Bossis, I.; Stallings, C.R.; Origoni, A.E.; Sullens, A.; Yolken, R.H. Coronavirus Immunoreactivity in Individuals With a Recent Onset of Psychotic Symptoms. Schizophr. Bull. 2009, 37, 101-107. [CrossRef]

12. Mao, L.; Wang, M.; Chen, S.; He, Q.; Chang, J.; Hong, Y.; Wang, D.; Li, Y.; Jin, H.; Hu, B. Neurological Manifestations of Hospitalized Patients with COVID-19 in Wuhan, China: A retrospective case series study. medExiv 2020. [CrossRef]

13. Mao, L.; Jin, H.; Wang, M.; Hu, Y.; Chen, S.; He, Q.; Chang, J.; Hong, C.; Zhou, Y.; Wang, D.; et al. Neurologic Manifestations of Hospitalized Patients With Coronavirus Disease 2019 in Wuhan, China. JAMA Neurol. 2020, 77, 683. [CrossRef]

14. Giorgianni, A.; Vinacci, G.; Agosti, E.; Mercuri, A.; Baruzzi, F. Neuroradiological features in COVID-19 patients: First evidence in a complex scenario. J. Neuroradiol. 2020, 47, 474-476. [CrossRef] [PubMed]

15. Nepal, G.; Rehrig, J.H.; Shrestha, G.S.; Shing, Y.K.; Yadav, J.K.; Ojha, R.; Pokhrel, G.; Tu, Z.L.; Huang, D.Y. Neurological manifestations of COVID-19: A systematic review. Crit. Care 2020, 24, 421. [CrossRef]

16. Sharifi-Razavi, A.; Karimi, N.; Rouhani, N. COVID-19 and intracerebral haemorrhage: Causative or coincidental? New Microbes New Infect 2020, 35, 100669. [CrossRef]

17. Benger, M.; Williams, O.; Siddiqui, J.; Sztriha, L. Intracerebral haemorrhage and COVID-19: Clinical characteristics from a case series. Brain Behav. Immun. 2020, 88, 940-944. [CrossRef] [PubMed]

18. Camacho, E.; LoPresti, M.A.; Bruce, S.; Lin, D.; Abraham, M.; Appelboom, G.; Taylor, B.; McDowell, M.; DuBois, B.; Sathe, M.; et al. The role of age in intracerebral hemorrhages. J. Clin. Neurosci. 2015, 22, 1867-1870. [CrossRef]

19. Parsons, N.; Outsikas, A.; Parish, A.; Clohesy, R.; Thakkar, N.; D'Aprano, F.; Toomey, F.; Advani, S.; Poudel, G. Modelling the Anatomical Distribution of Neurological Events in COVID-19 Patients: A Systematic Review. medRxiv 2020. [CrossRef]

20. Cordonnier, C.; Salman, R.A.-S.; Wardlaw, J.M. Spontaneous brain microbleeds: Systematic review, subgroup analyses and standards for study design and reporting. Brain 2007, 130, 1988-2003. [CrossRef] [PubMed]

21. Yates, P.A.; Villemagne, V.L.; Ellis, K.A.; Desmond, P.M.; Masters, C.L.; Rowe, C.C. Cerebral Microbleeds: A Review of Clinical, Genetic, and Neuroimaging Associations. Front. Neurol. 2014, 4, 205. [CrossRef]

22. Rabelo, L.A.; Alenina, N.; Bader, M. ACE2-angiotensin-(1-7)-Mas axis and oxidative stress in cardiovascular disease. Hypertens Res. 2011, 34, 154-160. [CrossRef]

23. Tikellis, C.; Bernardi, S.; Burns, W.C. Angiotensin-converting enzyme 2 is a key modulator of the renin-angiotensin system in cardiovascular and renal disease. Curr. Opin. Nephrol. Hypertens. 2011, 20, 62-68. [CrossRef]

24. Wrapp, D.; Wang, N.; Corbett, K.S.; Goldsmith, J.A.; Hsieh, C.-L.; Abiona, O.; Graham, B.S.; McLellan, J.S. Cryo-EM structure of the 2019-nCoV spike in the prefusion conformation. Science 2020, 367, 1260-1263. [CrossRef] [PubMed]

25. Tseng, Y.-H.; Yang, R.-C.; Lu, T.-S. Two hits to the renin-angiotensin system may play a key role in severe COVID-19. Kaohsiung J. Med. Sci. 2020, 36, 389-392. [CrossRef] [PubMed]

26. Yang, J.; Zheng, Y.; Gou, X.; Pu, K.; Chen, Z.; Guo, Q.; Ji, R.; Wang, Y.; Zhou, Y. Prevalence of comorbidities and its effects in patients infected with SARS-CoV-2: A systematic review and meta-analysis. Int. J. Infect Dis. 2020, 94, 91-95. [CrossRef]

27. Penney, L.; Galarneau, D. Peduncular hallucinosis: A case report. Ochsner J. 2014, 14, 450-452. [PubMed] 
28. Kosty, J.A.; Mejia-Munne, J.; Dossani, R.; Savardekar, A.; Guthikonda, B. Jacques Jean Lhermitte and the syndrome of peduncular hallucinosis. Neurosurg. Focus 2019, 47, E9. [CrossRef] [PubMed]

29. Schneider, R.C.; Crosby, E.C.; Farhat, S.M. Farhat Extratemporal lesions triggering the temporal-obe syndrome. J. Neurosurg. 1965, 22, 246-263. [CrossRef] [PubMed]

30. Yano, K.; Kuroda, T.; Tanabe, Y.; Yamada, H. Delayed Cerebral Ischemia Manifesting as Peduncular Hallucinosis after Aneurysmal Subarachnoid Hemorrhage-Three Case Reports-. Neurol. Med. Chir. 1994, 34, 593-596. [CrossRef]

31. Furuta, T.; Nobutou, H.; Nobutou, F. Peduncular hallucinosis due to a small hemorrhage around the substantia nigra: A case report. No Shinkei Brain Nerve 2002, 54, 423-426.

32. Kinoshita, Y.; Yasukouchi, H.; Harada, A.; Tsuru, E.; Okudera, T. Case report of traumatic hemorrhage from the anterior choroidal artery. No Shinkei Geka 2008, 36, 891-894.

33. Hashimoto, Y.; Kimura, K.; Yonehara, T.; Uchino, M.; Ando, M. A case of the brainstem tactile hallucinosis due to pontine hemorrhage. Rinsho Shinkeigaku 1995, 35, 286-289.

34. Julayanont, P.; Ruthirago, D.; Alam, K.; Alderazi, Y. Behavioral Disconnection Syndrome Manifesting as Combined Mania and Visual-Auditory Hallucinations Secondary to Isolated Right Thalamic Hemorrhage. J. Neuropsychiatry Clin. Neurosci. 2017, 29, 401-408. [CrossRef]

35. Shiga, K.; Makino, M.; Ueda, Y.; Nakajima, K. Metamorphopsia and visual hallucinations restricted to the right visual hemifield after a left putaminal haemorrhage. J. Neurol. Neurosurg. Psychiatry 1996, 61, 420-421. [CrossRef]

36. Machii, K.; Watanabe, Y.; Narita, Y.; Kuzuhara, S.; Mezaki, T. 123I-IMP SPECT findings of visual perseveration in a patient with old hemorrhage in the right occipital lobe. Rinsho Shinkeigaku 1994, 34, 823-826.

37. Nakajima, K. Clinicopathological study of pontine hemorrhage. Stroke 1983, 14, 485-493. [CrossRef] [PubMed]

38. Cohen, L.; Verstichel, P.; Pierrot-Deseilligny, C. Hallucinatory vision of a familiar face following right temporal hemorrhage. Neurology 1992, 42, 2052. [CrossRef]

39. Manford, M.; Andermann, F. Complex visual hallucinations. Clinical and neurobiological insights. Brain 1998, 121 Pt 10, 1819-1840. [CrossRef]

40. Varatharaj, A.; Thomas, N.; Ellul, M.A.; Davies, N.W.S.; Pollak, T.A.; Tenorio, E.L.; Sultan, M.; Easton, A.; Breen, P.G.; Zandi, M.; et al. Neurological and neuropsychiatric complications of COVID-19 in 153 patients: A UK-wide surveillance study. Lancet Psychiatry 2020, 7, 875-882. [CrossRef]

41. Mirfazeli, F.S.; Sarabi-Jamab, A.; Jahanbakhshi, A.; Kordi, A.; Javadnia, P.; Shariat, S.V.; Aloosh, O.; Almasi-Dooghaee, M.; Faiz, S.H.R. Neuropsychiatric manifestations of COVID-19 can be clustered in three distinct symptom categories. Sci. Rep. 2020, 10, 20957. [CrossRef] [PubMed]

42. Matschke, J.; Lütgehetmann, M.; Hagel, C.; Sperhake, J.P.; Schröder, A.S.; Edler, C.; Mushumba, H.; Fitzek, A.; Allweiss, L.; Dandri, M.; et al. Neuropathology of patients with COVID-19 in Germany: A post-mortem case series. Lancet Neurol. 2020, 19, 919-929. [CrossRef]

43. Mascolo, A.; Berrino, P.M.; Gareri, P.; Castagna, A.; Capuano, A.; Manzo, C.; Berrino, L. Neuropsychiatric clinical manifestations in elderly patients treated with hydroxychloroquine: A review article. Inflammopharmacology 2018, 26, 1141-1149. [CrossRef]

44. Janes, M.; Kuster, S.; Goldson, T.M.; Forjuoh, S.N. Steroid-induced psychosis. In Baylor University Medical Center Proceedings; Taylor \& Francis: London, UK, 2019; Volume 32, pp. 614-615.

45. Parra, A.; Juanes, A.; Losada, C.; Álvarez-Sesmero, S.; Santana, V.; Martí, I.; Urricelqui, J.; Rentero, D. Psychotic symptoms in COVID-19 patients. A retrospective descriptive study. Psychiatry Res. 2020, 291, 113254. [CrossRef]

46. Khuroo, M.S. Chloroquine and hydroxychloroquine in coronavirus disease 2019 (COVID-19). Facts, fiction and the hype: A critical appraisal. Int. J. Antimicrob. Agents 2020, 56, 106101. [CrossRef] [PubMed]

47. Lee, D.T.S.; Wing, Y.K.; Leung, H.C.M.; Sung, J.J.Y.; Ng, Y.K.; Yiu, G.C.; Chen, R.Y.L.; Chiu, H.F.K. Factors Associated with Psychosis among Patients with Severe Acute Respiratory Syndrome: A Case-Control Study. Clin. Infect. Dis. 2004, 39, 1247-1249. [CrossRef] [PubMed]

48. London, J.; Sutherland, J. John Barleycorn: 'Alcoholic Memoirs'; Oxford University Press: Oxford, NY, USA, 2009.

49. Greenberg, D.M.; Lee, J.W. Psychotic manifestations of alcoholism. Curr. Psychiatry Rep. 2001, 3, 314-318. [CrossRef]

50. Winstock, A.R.; Reed, K.D. Alcohol misuse. In Core Psychiatry; Elsevier: Amsterdam, The Netherlands, 2012 ; pp. $421-438$.

51. Dilling, H.; Freyberger, H.J. Taschenführer zur ICD-10-Klassifikation Psychischer Störungen: Mit Glossar und Diagnostischen Kriterien Sowie Referenztabellen ICD-10 vs. ICD-9 vs. DSM-IV-TR. Nach dem Englischsprachigen Pocket Guide von J. E. Cooper, 9th ed.; Aktualisierte Auflage unter Berücksichtigung der Änderungen gemäß ICD-10 GM (German Modification); Hogrefe: Bern, Switzerland, 2019; ISBN 978-3456859927.

52. Jesse, S.; Bråthen, G.; Ferrara, M.; Keindl, M.; Ben-Menachem, E.; Tanasescu, R.; Brodtkorb, E.; Hillbom, M.; Leone, M.; Ludolph, A. Alcohol withdrawal syndrome: Mechanisms, manifestations, and management. Acta Neurol. Scand. 2016, 135, 4-16. [CrossRef] [PubMed]

53. Ma, H.; Zhu, G. The dopamine system and alcohol dependence. Shanghai Arch. Psychiatry 2014, 26, 61-68.

54. Laine, T.P.J.; Ahonen, A.; Torniainen, P.; Heikkilä, J.; Pyhtinen, J.; Räsänen, P.; Niemelä, O.; Hillbom, M. Dopamine transporters increase in human brain after alcohol withdrawal. Mol. Psychiatry 1999, 4, 189-191. [CrossRef] 